\title{
O problema da causalidade: um desequilíbrio da crítica*
}

\author{
Maurício C. Keinert**
}

Resumo: O texto procura mostrar, acompanhando a tese de Gérard Lebrun em seu livro Kant e o fim da Metafísica, uma possível ligação entre o "Apêndice à Dialética transcendental" da Crítica da razão pura e a "Primeira introdução à Crítica do Juízo" por meio do problema da finalidade na unidade sistemática da natureza.

Palavras-chave: Idéia - causalidade - Juízo - sistema - crítica

Em um determinado momento do "Apêndice à dialética transcendental", Immanuel Kant, discorrendo acerca do uso da idéia de um ser supremo, diz: "O primeiro vício que resulta do uso da idéia de um ser supremo, não de modo simplesmente regulador, mas constitutivo (o que é contrário à natureza de uma idéia), é o da razão preguiçosa (ignava ratio)" (Kant 1, p. 562; p. 453-4) ${ }^{1}$. Mesmo que descontextualizado, tal trecho é um bom indicador da preocupação do autor em relação à possibilidade de um uso constitutivo das idéias reguladoras da razão. O poder da crítica se contrapõe à "preguiça da razão" justamente pelo fato de investigar e, por conseguinte, autorizar um uso que não seja permissivo, que não leve a razão a se enveredar pelas malhas do dogmatismo. Se, no entanto, esse pequeno trecho revela uma preocupação que é constante ao longo do Apêndice, ele se mostra um tanto estranho na medida em que foi escrito logo após Kant ter definido que a idéia do ser supremo, ainda que reguladora, torna possível ver na natureza, entendida como uma unidade sistemática, uma certa

* Este texto é uma versão das duas primeiras partes do relatório final de Iniciação Científica apresentado à FAPESP em 1998.

** Mestrando do Departamento de Filosofia - FFLCH-USP. 
finalidade. O que é estranho, se é que se pode falar assim, é essa ligação entre a idéia de um ser supremo e a possibilidade de uma teleologia na natureza.

A tese central de Gérard Lebrun em seu livro Kant e o fim da metafísica se mostra decisiva como um guia desse problema: analisar e caracterizar a teleologia em Kant depende do estabelecimento de uma ligação entre o "Apêndice à dialética transcendental" da Crítica da razão pura e a "Primeira introdução à Crítica do Juízo". Mais precisamente, para Lebrun, é preciso investigar até que ponto a intenção pressuposta pelo sujeito transcendental na idéia teológica (do ser supremo) não esconde uma nova instância, ainda insuspeita para o Kant da primeira Crítica, mais adequada para o tratamento da teleologia. No Apêndice, a pressuposição de uma intenção do Deus enquanto idéia causaria um mau funcionamento nas engrenagens do mecanismo crítico kantiano que, em última instância, não o deslocaria totalmente do cenário da metafísica dogmática. A "Primeira introdução à Crítica do Juízo" seria assim um novo lugar para Kant repensar esse problema que, ainda em 1787, não era visto como tal, ou ainda, nas palavras de Lebrun: "O fato de que a Primeira introdução seja uma retomada do fim da Dialética parece-nos, ao contrário, fundamental: ele indica que, ao final desta, a metafísica clássica não estava completamente destruída, ou também que a Crítica ainda não tinha encontrado seu equilíbrio" (Lebrun 5, p. 323).

É exatamente essa alusão ao equilíbrio da Crítica feita por Lebrun que chama a atenção. Com o advento da terceira Crítica, aquela instância ainda insuspeita que estaria por trás do modo pelo qual Kant trabalhou a noção de finalidade se revela sob a insígnia da reflexão, e o Juízo passa a ter um novo papel dentro do sistema kantiano - reequilibrando o mecanismo crítico. Kant, com isso, instaura uma nova abordagem a respeito da finalidade, o conceito de fim não é mais pensado por meio de uma intencionalidade (ela não diz mais respeito ao âmbito delimitado pela crítica), mas deve ser pensado por meio do juízo reflexionante. Na "Primeira introdução" ele opera essa mudança de modo explícito quando afirma: "O conceito de fins naturais é, pois, exclusivamente um conceito do Juízo reflexionante para seu próprio uso, para rastrear a vinculação causal em objetos da experiência. Por um princípio teleológico de explicação da possibilidade interna de certas formas naturais, é deixado indeterminado se a finalidade das mesmas é intencional ou não intencional" (Kant 2, p. 74; p. 236). É interessante notar, nesse trecho, o cuidado de Kant em inserir o juízo reflexionante na vinculação causal dos objetos da experiência. Essa preocupa- 
ção parece ser o centro da mudança operada por ele em relação à finalidade e à indeterminação da intencionalidade.

A intencionalidade, no Apêndice, deriva de um tipo específico de causalidade: o enfoque é dado na relação entre a razão e os conceitos do entendimento (para se pensar uma sistematicidade dos objetos da experiência) articulada por uma analogia. Mas essa analogia, na segunda parte do Apêndice, é apresentada em dois momentos: num primeiro é a garantia de uma regulação, por parte da razão, da sistematicidade da natureza; num segundo momento essa sistematicidade é garantida ainda conforme a um fim. O ponto-chave dessa analogia é apresentado por Kant com a terceira idéia da razão pura: "na verdade, o que nos dará o poder ou sequer o direito de acreditar num ser de suprema perfeição e absolutamente necessário por sua natureza, ou de afirmá-lo em si através do seu puro conceito, senão o mundo, em relação ao qual unicamente esta suposição pode ser necessária? Aqui se mostra, claramente, que a idéia desse ser, bem como todas as idéias especulativas, significam somente que a razão obriga a considerar todo o encadeamento no mundo segundo princípios de uma unidade sistemática, ou seja, como se fossem todas elas oriundas de um único ser, que tudo abrange como causa suprema e omni-suficiente" (Kant 1, p. 560; p. 452). A suposição do ser perfeito, de uma racionalidade divina, nasce de sua analogia com a razão humana: supor um ser organizador do encadeamento no mundo, dos objetos da experiência, é permitido na medida em que é um análogo do próprio funcionamento da racionalidade do sujeito transcendental. Como Lebrun aponta, é nos Prolegômenos, mais especificamente numa nota do parágrafo 58, que Kant deixa isso mais claro: "Direi: a causalidade da causa suprema é, em relação ao mundo o que a razão humana é relativamente às suas obras de arte. No entanto, a natureza da causa suprema permanece-me desconhecida: comparo somente o seu efeito que me é conhecido (a ordem do mundo) e a sua conformidade à razão com os efeitos também de mim conhecidos da razão humana e dou, por isso, à causa suprema o nome de razão, sem portanto the atribuir como sua propriedade o que precisamente entendo no homem sob esta expressão ou qualquer outra coisa que me é conhecida" (Kant 3, p. 155; p. 360). Ora, a analogia se estabelece a partir da seguinte relação: à medida que existem efeitos, conhecidos do homem, que tiveram como causa a razão humana, a ordem do mundo, o seu encadeamento e a sua sistematização, pode ser pensada analogamente como o efeito de uma razão suprema. Kant deixa 
claro nos Prolegômenos que não se trata de conhecer a natureza da causa que causou essa sistematização mas, a partir do momento em que a analogia é estabelecida, pode-se pensá-la como racional. Para ele, isso é importante porque, mesmo não se podendo conhecer uma unidade sistemática do mundo, é possível dar-lhe um significado racional, algo concebível pela razão que sirva de regulação para a inserção do sujeito na aparente totalidade do mundo e na sua relação com os objetos da experiência.

No entanto, no segundo momento, Kant vincula à analogia uma unidade sistemática do mundo conforme a um fim. A analogia passa a ter de dar conta também de um nexus finalis do mundo. Mais ainda, a finalidade, garantida pela terceira idéia da razão, ganha um papel preponderante no que diz respeito à sistematização do mundo: "Esta unidade formal suprema, fundada unicamente em conceitos racionais, é a unidade das coisas conforme a um fim, e o interesse especulativo da razão impõe a necessidade de considerar a ordenação do mundo como se brotasse da intenção de uma razão suprema. Com efeito, um tal princípio abre à nossa razão, aplicada ao campo das experiências, perspectivas totalmente novas de ligar as coisas do mundo segundo leis teleológicas e, deste modo, alcançar a máxima [grifo nosso] unidade sistemática" (Kant 1, p. 560; p. 452). A intenção do ser supremo, considerado em idéia, é aquilo que, para Kant, dá a garantia de se alcançar a máxima unidade sistemática do mundo.

O estabelecimento da analogia traz, portanto, um princípio regulador para a razão poder sistematizar o conhecimento do entendimento. Esse princípio é tanto a garantia de uma unidade sistemática da natureza quanto a garantia de uma unidade sistemática da natureza conforme a um fim. Lebrun aponta o problema do Apêndice justamente na articulação da passagem de uma garantia à outra. A inserção da finalidade na unidade sistemática da natureza seria, segundo ele, mal explicada. "No Apêndice, o deslize da unidade sistemática para a unidade final permanece ambíguo e mal justificado. Que o todo da natureza forma um sistema: essa pressuposição, afinal, deveria bastar; ela apareceria claramente como uma ficção útil. Mas que o todo da natureza, passa a ser pensado como um sistema, exija o esquema tecnológico, essa é uma pressuposição suplementar - mesmo se estruturalmente indispensável - que faz ressurgir a idéia de uma demiurgia pelo menos imaginável" (Lebrun 5, p. 319).

Nesse último trecho citado de Kant e o fim da metafísica, Lebrun, ao comentar a falta de justificação do "deslize" da unidade sistemática à unidade 
final, põe em contraposição duas formas antagônicas, a seu ver, com as quais Kant trata a questão da unidade sistemática da natureza: a analogia tratada enquanto um simbolismo e a analogia técnica. A segunda seria uma conseqüência mal justificada da primeira e é isso que incomoda o comentador francês. A analogia tratada enquanto um simbolismo nasceria, assim como na moral, da possibilidade do sujeito adotar um segundo ponto de vista, o ponto de vista do ser que está posto fora do mundo ${ }^{2}$. Porém, essa adoção de um segundo ponto de vista se estabelece a partir da relação existente entre a ordem do mundo e o efeito de inteligibilidade que ela suscita no sujeito e não da relação do mundo com a causa da qual ela seria efeito (cf. Lebrun 5, p. 306). Ora, essa diferenciação é importante na medida em que a postulação de um princípio organizador, do ser fora do mundo, não é tratada como constitutiva (não há um conhecimento determinante e objetivo deste ser) mas tratada subjetivamente, ou seja, através do efeito de inteligibilidade que ela suscita no sujeito - regulando assim, para ele, uma totalidade que lhe aparece. Kant, na primeira parte do Apêndice, faz a ligação da unidade da razão com essa postulação não constitutiva de uma idéia: "Esta unidade da razão pressupõe sempre uma idéia, a da forma de um todo do conhecimento que precede o conhecimento determinado das partes e contém as condições para determinar a priori o lugar de cada parte e sua relação com as outras. Esta idéia postula, por conseguinte, uma unidade perfeita do conhecimento do entendimento, mercê da qual este não é apenas um agregado acidental, mas um sistema encadeado segundo leis necessárias. Não se pode propriamente dizer que esta idéia seja o conceito de um objeto, mas sim o da unidade completa destes conceitos, na medida em que esta unidade serve de regra do entendimento" (Kant 1, p. 535; p. 428).

É importante notar que, ainda nesse ponto do Apêndice, Kant não vincula a idéia da razão à finalidade. A possibilidade de a razão poder dar regras ao entendimento no que diz respeito à totalidade da natureza constitui aquilo que ele chama de aparência transcendental. Ora, a idéia não é um conceito de objeto, não pode ser determinada, mas, enquanto regulação, serve para que, subjetivamente, o entendimento possa trabalhar com uma totalidade sistemática da natureza. Por mais paradoxal que possa parecer, a aparência dessa totalidade é necessária ${ }^{3}$. Se se acompanhar a tese de Lebrun, vê-se no entanto em que consiste essa necessidade da aparência: Kant procura redimensionar conceitos que foram abordados pela Analítica transcendental numa nova jurisdição, a 
do supra-sensível. Dessa forma, aqueles conceitos que antes estavam vinculados à possibilidade de determinação de objetos do conhecimento, no "jogo" estabelecido entre entendimento (imaginação) e sensibilidade pela Analítica transcendental, passam a ser tratados numa nova relação entre razão e entendimento. Essa nova relação trata dos conceitos exclusivamente do ponto de vista formal, negativamente, uma vez que a sensibilidade, a possibilidade de dar uma "matéria" aos conceitos do entendimento, é descartada nessa nova jurisdição. A necessidade da Aparência revela-se duplamente: no imperativo do entendimento poder trabalhar regulando-se por meio de uma unidade sistemática, assim como também nesse redirecionamento dado pela razão de seus conceitos.

A terceira idéia da razão, Deus, surge, portanto, da possibilidade de se utilizar conceitos puros do entendimento, abstraídos de qualquer fator sensível, para pensá-la. A causalidade da causa do mundo é assim um dos conceitos utilizados por Kant para pensar a unidade sistemática dada por Deus. Lebrun, sobre isso, acrescenta: "se, como toda categoria, a causalidade só tem um uso empírico, ela conserva, nós o sabemos, um sentido transcendental independente desse uso. É por isso que não é absurdo aplicar metaforicamente a 'simples categoria' de causalidade à relação entre o 'ser supra-sensível $=\mathrm{X}$ ' e o mundo sensível: esses predicados (substância, causa, etc.) são simples categorias que não dão dele um conceito determinado, mas exatamente por isso (eben dadurch) ele não está limitado às condições da sensibilidade' (IV, 358)" (Lebrun 5, p. 308). O que Lebrun procura mostrar aqui é que o conceito de causa é retirado do seu uso empírico "comum" para dar um sentido à relação entre o ser suprasensível e o mundo sensível ${ }^{4}$. O conceito de causa não determina mais, mas é o ponto central para que a analogia se estabeleça e a aparência transcendental ganhe um sentido para a regulação do entendimento diante de uma unidade sistemática da natureza.

Grosso modo, essa seria a caracterização que Lebrun faz daquilo que entende ser o simbolismo analógico. Se a idéia reguladora é chamada pelo nome "Deus" é justamente porque esse nome não possui mais um sentido ontológico, mas apenas um sentido simbólico. E o simbólico aqui se constitui em dois movimentos interligados: na própria forma pela qual é construída a analogia e a relação, proporcionada por ela, entre a unidade sistemática dada pela razão - a postulação da idéia - e o entendimento. De forma mais clara, Lebrun 
conclui: "Se Kant reintroduz um teísmo simbólico, é porque ele estima que o teísmo dogmático está definitivamente excluído e que a analogia, tal como ele a redefine, torna impossível qualquer retorno para aquém de Hume. Deus não é mais provado por suas obras: é a ordem da natureza que me aparece como divina" (Lebrun 5, p. 311). O teísmo simbólico retira qualquer possibilidade de um conhecimento teorético de Deus, porque se funda em uma analogia entre a razão divina e a razão humana não a partir do conhecimento das obras de um Deus artesão, mas na forma com que o sujeito compreende a aparente ordem do mundo através da categoria de causa.

No entanto, se se retomar a nota do parágrafo 58 dos Prolegômenos e a segunda parte do Apêndice, pode-se ver que a noção de causalidade que está orientando o sentido da analogia tem de pressupor a noção de técnica quando passa a tratar da teleologia. Para Lebrun, a passagem da analogia simbólica para a analogia técnica se dá justamente no momento em que a garantia de uma ordem da unidade sistemática tem de levar em conta também a finalidade dessa unidade. É nesse momento que a noção de causalidade, embutida no Deus em idéia, acaba por desvelar uma característica que seria impensável dentro da estrutura do simbolismo analógico: na causa do mundo está implícita a necessidade de um autor desse mundo. E é esse autor que, por meio de uma intenção, garante o máximo de unidade sistemática da natureza por meio de um nexus finalis. A causalidade do princípio da razão, estruturada na analogia por meio da relação entre a ordem do mundo e o efeito de inteligibilidade que ele suscita no sujeito, perde a sua força. Lebrun aponta o problema da seguinte maneira: "Nós pudemos descrever o Ideal transcendental como um compromisso entre a restrição da razão teórica ao uso empírico e a exigência de totalidade sistemática. Mas o esquema da causalidade racional, por mais inofensivo e retórico que seja, reintroduz o pathos da produção técnica. Sem a relação da obra com o operário, não se pode pensar o mundo como totalidade sistemática; desde então, o modelo da finalidade consciente adquire uma importância que até então não tinha na obra de Kant" (Lebrun 5, p. 313). O teísmo simbólico, que, na ótica do comentador, era o símbolo da destruição da teologia dogmática ainda não consegue se desvincular totalmente dessa última. A inserção da finalidade na natureza reintroduz novamente "vestígios do Deus clássico".

O que parece estar nas entrelinhas do livro de Lebrun, no que se refere ao "Apêndice à dialética transcendental", é que, no momento em que Kant 
descobre a radicalidade da Aparência transcendental, ele não consegue assumi-la inteiramente. A intenção do Deus em idéia faz com que ela perca, de certo modo, o seu valor, pois o conceito de causalidade que aí está envolvido acaba por ultrapassar o campo da experiência possível permitido pela crítica. A permissão de utilizar o conceito de causalidade, na sua forma pura, sem qualquer tipo de ligação com a sensibilidade, para poder postular a idéia de uma unidade sistemática da natureza fica obscurecida. Kant não deixa claro como esse conceito de causalidade permite a noção de uma intencionalidade. A aparência transcendental, entendida pelo viés teleológico, já não é mais aquilo que aparece ao sujeito mas, ao contrário, ela acaba por esconder um autor, a causa do mundo, que pretendia liquidar junto com a metafísica clássica. A causalidade passa a depender mais da causa do que da relação de inteligibilidade que ela deveria causar no sujeito. A crítica que, em princípio, não permitiria isso, enfraquece-se ao obscurecer a relação de causalidade. Estaria aberta à metafísica a porta dos fundos da Crítica da razão pura - Deus e o mundo em si atuariam por trás do véu da Aparência transcendental.

Mas não é isso que ocorre se se compreender a "Primeira introdução" como um "escrúpulo crítico". Nela, Kant deixa a questão da intencionalidade indeterminada e, em nenhum momento, encontram-se passagens como "deve ser-vos perfeitamente indiferente, quando observardes essa unidade [sistemática e teleológica], dizer que Deus assim o quis na sua sabedoria ou que a natureza assim o ordenou sabiamente" (Kant 1, p. 568). Pelo contrário, a figura da idéia de Deus desaparece deixando apenas a natureza como fonte de investigação do filósofo. Isso porque a noção de analogia é redefinida, já que o juízo reflexionante passa a ter um papel preponderante na indagação acerca da unidade sistemática e teleológica da natureza. É nesse sentido que Kant, na "Primeira introdução", após deixar indeterminada a questão da intencionalidade do princípio teleológico, escreve: "O juízo que afirmasse um dos dois [a intencionalidade ou a não intencionalidade] não seria apenas reflexionante, mas determinante, e o conceito de um fim natural também não seria mais um mero conceito do Juízo, para uso imanente (da experiência), mas estaria vinculado com um conceito da razão, de uma causa posta acima da natureza e atuando intencionalmente, cujo uso é transcendente, quer nesse caso se julgue afirmativa, ou mesmo negativamente" (Kant 2, p. 74; p.236-7). Vê-se nessa citação de Kant a preocupação de desvincular a possibilidade de poder julgar 
a intencionalidade a partir de um conceito de razão. A analogia do Deus em idéia é posta de lado, pois causa problemas com a inserção da finalidade na sua estrutura. Não obstante, poder-se-ia perguntar aqui, qual é o centro dessa mudança operada por Kant?

Por ora, essa questão encontra uma primeira resposta naquela primeira citação da "Primeira introdução" feita acima: "Por um princípio teleológico de explicação da possibilidade interna de certas formas naturais, é deixado indeterminado se a finalidade das mesmas é intencional ou não intencional'. Há uma mudança na forma de Kant encarar a questão da causalidade dos objetos da experiência: o "foco especulativo", que procura pelo princípio teleológico não está mais direcionado àquela causalidade da idéia transcendental em relação aos objetos do entendimento, mas à possibilidade interna de certas formas naturais. É na configuração interna dessas formas naturais que Kant encontra uma nova forma de abordar a questão da causalidade no âmbito do supra-sensível. E é o Juízo que passa a ter a tarefa de organizar a articulação da unidade sistemática dos objetos da experiência do entendimento conforme a um fim.

É a noção de organismo que permite a Kant propor um novo modelo de causalidade para a teleologia. Melhor dizendo: é por meio da reflexão acerca do organismo que Kant pode propor essa nova forma de causalidade. No entanto, se é na "Primeira introdução" que Kant procura abordar o organismo a partir do juízo reflexionante, no Apêndice ele já aparece como exemplo. É famosa a passagem em que Kant, logo após discorrer sobre a unidade sistemática da natureza conforme a um fim, exemplifica essa através da fisiologia: "Eis porque a fisiologia (dos médicos) também amplia o seu tão reduzido conhecimento empírico das finalidades da estrutura de um corpo orgânico, mediante um princípio inspirado simplesmente pela razão pura, até ao ponto de admitir ousadamente, e com a aprovação de todos os entendidos, que tudo no animal tem sua utilidade e a sua intenção boa, pressuposto este que, se fosse constitutivo, iria muito mais longe que o que nos é legítimo admitir pela observação feita até hoje; de onde se pode depreender que não é mais que um princípio regulador da razão para atingir a mais alta unidade sistemática, mediante a idéia da causalidade final da causa suprema do mundo, como se esta, enquanto inteligência suprema, fosse autora de tudo segundo o mais sábio desígnio" (Kant 1, p. 561-2; p.453).

À luz da terceira crítica, trechos como esse da Crítica da razão pura parecem verdadeiramente estranhos. É difícil compreender, pelo esquema da 
causalidade aí exposto, a relação que Kant estabelece entre o corpo orgânico e o autor do mundo (explícita no trecho acima). A desconfiança de Lebrun acerca do obscurantismo dessas páginas finais do Apêndice é procedente. Para ele, o organismo é o índice daquela passagem mal explicada da analogia simbólica à analogia técnica: “O que quer que ele seja, é certo que o instrumento necessário para a compreensão da unidade sistemática desvela a finalidade, quando the pedíamos que garantisse a ordem. No Apêndice à Dialética, os exemplos são todos emprestados aos fatos orgânicos, uma vez estabelecida a necessidade da analogia técnica. A unidade da natureza da qual exclusivamente se tratava até aqui (o equivalente do $1^{\circ}$ Princípio de 1763) apaga-se diante da 'maior unidade sistemática', 'a unidade formal suprema' em nome da qual podemos ligar as coisas segundo leis teleológicas” (Lebrun 5, p. 313). Nessa interpretação de Lebrun o organismo aparece como o exemplo mais claro da analogia técnica: é porque há um autor do mundo que possui um tipo específico de causalidade, que o anatomista pode sempre trabalhar com a hipótese da finalidade quando está diante de um corpo orgânico.

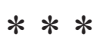

Do ponto de vista do esquema interpretativo de Lebrun, vê-se que a passagem do Apêndice à Primeira introdução se dá justamente no "deslize" do simbolismo analógico para a analogia técnica, mal justificado por Kant. O organismo seria, assim, o exemplo bem acabado dessa falta de justificação, pois é ele que, na primeira crítica, revela a falência de um tipo de causalidade que, necessariamente (na forma pela qual é pensada), pressupõe um autor do mundo para a garantia de uma finalidade dentro de uma natureza sistemática. É nesse momento que a própria noção de crítica acaba por se desequilibrar dentro do sistema kantiano. A "Primeira introdução", portanto, seria o lugar em que Kant tem de repensar e recolocar o problema da teleologia e, como foi visto, é principalmente a questão da intenção divina que tem de ser abordada; é ela que está no centro da problemática do Apêndice.

Mas é o afastamento da noção de intenção, ou melhor, a indeterminação da possibilidade de se poder julgar uma finalidade na natureza de forma intencional ou não intencional que acaba por remodelar aspectos importantes do sistema kantiano. O Juízo, o resultado dessa reflexão de Kant na "Primeira introdução", 
deflagra uma nova constelação de forças no que diz respeito às relações entre sensibilidade, entendimento e razão na estrutura da obra kantiana (pensando aqui tanto o juízo estético quanto o teleológico). Nessa medida, aquilo que aparecia como um problema pontual no final da "Dialética transcendental", com a "Primeira introdução" deflagra um certo redirecionamento da obra de Kant.

Não se pode dizer simplesmente que a "Primeira introdução" é a solução dos problemas apresentados pelo Apêndice, mas, ao contrário, é a radicalização, por parte de Kant, de sua reflexão diante desses problemas. Nesse sentido, a "Primeira introdução", mais do que solução, norteia a forma pela qual Kant busca pensar os problemas advindos da teleologia (problemas esses que já estão em germe no "Apêndice à dialética transcendental"). O estabelecimento de um "diálogo" entre os dois textos seria assim uma forma de tentar indicar algumas questões que estão por trás da noção de teleologia, nos dois textos.

O primeiro parágrafo da "Primeira introdução" já é bastante revelador: "Se filosofia é o sistema do conhecimento racional por conceitos, já com isso ela se distingue suficientemente de uma crítica da razão pura, que contém, por certo, uma investigação filosófica da possibilidade de um conhecimento como esse, mas não pertence, como parte, a um tal sistema, tanto que somente ela delineia e verifica a idéia do mesmo" (Kant 2, p. 31; p. 195). Filosofia de um lado e crítica do outro, a segunda verificando a possibilidade da primeira. É interessante questionar por que Kant retoma, já no primeiro parágrafo, esta relação que o guia desde o começo de seu período crítico. Poder-se-ia aventar aqui a importância, nesse momento, de uma diferenciação que, apesar de num primeiro momento parecer óbvia, merece atenção: a filosofia está sendo caracterizada aqui como o sistema do conhecimento racional por conceitos e, só por esse motivo, ela já se diferencia de uma crítica da razão pura. Se se tomar o problema da finalidade, a forma com que Kant trabalha a causalidade no Apêndice, vê-se ali um conceito da razão, embora indeterminado, que, "autorizado" pela crítica, dava sentido ao entendimento trabalhar com uma unidade sistemática da natureza conforme a um fim. Não seria esse primeiro parágrafo um indício de um deslocamento que Kant pretende realizar no que diz respeito aos conceitos da razão? A invocação da noção de crítica não seria a necessidade de uma nova verificação dos limites dos conceitos da razão quando essa busca lançar-se para além da jurisdição do conhecimento científico? 
É possível responder a essas questões de forma positiva se se contextualizar esse parágrafo principalmente em relação às duas primeiras partes da "Primeira introdução" . No movimento que se segue a ele, Kant procura, em primeiro lugar, fazer a divisão do sistema em duas partes: formal e material, "das quais a primeira (a lógica) contém meramente a forma do pensar em um sistema de regras, a segunda (parte real) toma sistematicamente em consideração os objetos sobre os quais se pensa, na medida em que é possível um conhecimento racional dos mesmos a partir de conceitos" (Kant 2, p. 31; p. 195). Dividido assim o sistema, Kant procura então subdividir a parte real em filosofia teórica e prática de acordo com os objetos de que tratam: a filosofia da natureza contendo princípios puros e empíricos, enquanto que a dos costumes contém apenas os primeiros. Por meio dessa subdivisão, Kant procura esclarecer um "grande mal-entendido", a saber: aquilo que deve ser entendido por prático. Esse esclarecimento é importante na medida em que traz para as divisões do sistema um elemento novo, ou ainda, um elemento que nasce da necessidade desse esclarecimento: as proposições técnicas. Kant escreve: "Em suma: todas as proposições práticas que derivam do arbítrio, como causa, aquilo que a natureza pode conter, pertencem, em seu conjunto, à filosofia teórica, como conhecimento da natureza; somente as que dão à liberdade a lei são, segundo o conteúdo, especificamente diferentes daquelas. Pode-se dizer das primeiras: constituem a parte prática de uma filosofia da natureza, mas somente estas últimas fundamentam uma filosofia prática em particular" (Kant 2, p. 33; p. 197). Kant está preocupado aqui especificamente com proposições da política e economia política, regras de economia doméstica, de comportamento, prescrições de higiene, dietética, etc., que poderiam ser chamadas de proposições práticas, no sentido de serem regras de ações nesses diferentes campos. Mas, se de fato essas proposições podem ser chamadas práticas, por direito elas ferem os limites que dividem a filosofia prática da teórica, pois essas proposições, no limite, são meras conseqüências do conhecimento teórico. Se há uma diferenciação segundo o modo de representação dessas proposições em relação às proposições teóricas, o mesmo não acontece quanto ao conteúdo. Essa diferenciação de conteúdo só se verificaria se essas proposições considerassem a liberdade sob leis. Mas não é isso que acontece, já que o conteúdo de que trata esse tipo de proposição faz parte da filosofia da natureza, ou seja, essas proposições "nada mais são do que a teoria daquilo que pertence à natureza das 
coisas, apenas aliada ao modo como podem ser engendradas por nós segundo um princípio, isto é, representada a possibilidade das mesmas por uma ação do arbítrio (que, mesmo assim, faz parte das causas naturais)" (Kant 2, p. 32; p. 196). Assim, o que está no cerne da questão é o modo pelo qual o arbítrio age: quando de acordo com a liberdade sob leis, há uma proposição prática no sentido forte; quando, porém, de acordo com aquilo que concerne às naturezas das coisas, ao conhecimento dessas, há uma proposição "prática” teórica.

Para Kant, "proposições práticas, pois, que segundo o conteúdo se referem meramente à possibilidade de um objeto representado (por ação do arbítrio), são somente aplicações de um conhecimento teórico completo e não podem constituir uma parte particular de uma ciência" (Kant 2, p. 34; p. 198). Se, no entanto, não se distinguem do campo da ciência teórica, possuem uma característica própria, são proposições de execução, ou seja, a partir de princípios teóricos, executam determinadas ações (sejam elas resoluções de problemas geométricos, experimentações físicas, etc.). É dessa forma que Kant pode chamá-las de proposições técnicas, "pois pertencem à arte de instituir aquilo de que se quer que seja, a qual, em uma teoria completa, é sempre uma mera conseqüência, e não uma parte, subsistente por si, de algum modo de instrução" (Kant 2, p. 35; p. 200).

Logo após resolver o mal-entendido das proposições práticas, Kant refere-se a um outro tipo de uso em que a expressão técnica pode ser empregada: "Mas futuramente empregaremos também a expressão 'técnica' onde objetos da natureza, às vezes, são julgados somente como se sua possibilidade se fundasse em arte, casos em que os juízos não são nem teóricos, nem práticos (na significação que acaba de ser apresentada), pois não determinam nada da índole do objeto, nem do modo de produzi-lo, mas através deles a natureza mesma é julgada meramente por analogia com uma arte, e aliás na referência subjetiva a nossa faculdade-de-conhecimento, e não na referência objetiva aos objetos" (Kant 2, p. 36; p. 200-1). Numa primeira leitura desse trecho, parece ser estranho o fato de Kant gastar tanta tinta resolvendo o mal-entendido das proposições práticas, diferenciando-as das proposições técnicas para, por fim, utilizar um outro emprego da expressão "técnica" em que elementos básicos da "Primeira introdução" começarão a ser abordados. Poder-se-ia aqui aventar uma hipótese para a ligação das duas formas utilizadas para o emprego da expressão "técnica": em primeiro lugar, o que salta aos olhos é que a expressão, 
quando utilizada para se referir a proposições "práticas" teóricas, traz consigo a idéia de arte e de execução de algo; nesse sentido, a natureza julgada como arte seria a natureza que executa algo. Em segundo lugar, poder-se-ia dizer também que, por trás das proposições técnicas, como também das práticas, há um ato de reflexão do sujeito diante dos princípios e conteúdos relativos às proposições em questão. Aliás, é exatamente pela forma com que o arbítrio age que Kant diferencia as duas formas de proposições práticas, dando a entender que poderia haver uma reflexão do arbítrio em sua ação: em agir de acordo com princípios teóricos (da natureza) ou práticos (a liberdade) ${ }^{6}$. Nesse sentido, na técnica da natureza está implícita uma reflexão do sujeito, que se dá na forma do julgamento de objetos da natureza.

Por outro lado, no entanto, se se pode encontrar essas semelhanças nos dois usos, Kant precisa marcar bem a diferença, no sentido de caracterizar bem o segundo emprego de "técnica" nessa forma em que os objetos da natureza são julgados - não há mais a possibilidade de determinação, implícita nas proposições técnicas. Nesse sentido, os juízos não dizem respeito nem à parte teórica nem à prática, mas julgam os objetos da natureza como se esta fosse considerada enquanto arte, em referência subjetiva à nossa faculdade de conhecimento. Kant procura esclarecer isso quando escreve: "Aqui não denominaremos técnicos, por certo, os juízos mesmos, mas sim o Juízo, a faculdade de julgar, sobre cujas leis eles se fundam, e, em conformidade com este, também à natureza denominaremos técnica, técnica esta que, como não contém nenhuma proposição objetivamente determinante, também não constitui uma parte da filosofia doutrinal, mas somente da crítica de nossa faculdadede-conhecimento" (Kant 2, p.36; p. 201). Há aqui uma relação de dependência dos juízos em relação ao Juízo: é esse que, enquanto faculdade de julgar, dita leis para a fundamentação dos demais tipos de juízos. É por isso que Kant o denomina técnico, pois é por meio da atividade de reflexão, que lhe é própria, que há a possibilidade de fundamentar os outros tipos de juízos. Mais do que isso, é por meio dele que esse novo tipo de investigação acerca dos objetos da natureza pode ser empreendido: a natureza tem de ser investigada de forma reflexiva.

Na segunda parte da "Primeira introdução", Kant começa por incorporar o Juízo, não na divisão do sistema da filosofia, mas na divisão do sistema das faculdades superiores do conhecimento (que funda a filosofia, como diz o título 
dessa segunda parte). Trata-se assim de uma crítica da razão pura segundo sua faculdade de pensar (não há aqui o modo-de-intuição puro); Kant divide a representação sistemática da faculdade-de-pensamento em três partes, a saber: "primeiramente a faculdade do conhecimento do universal (das regras), o entendimento, em segundo lugar a faculdade da subsunção do particular sob o universal, o Juízo, e em terceiro lugar a faculdade da determinação do particular pelo universal (da derivação a partir de princípios), isto é, a razão" (Kant 2, p. 37; p. 201). O Juízo, apresentado entre entendimento e razão, passa a ter uma função distinta desses: a subsunção do particular sob o universal. Por conseguinte, se o entendimento fornece a priori leis da natureza e a razão, leis da liberdade, é de se esperar que o Juízo, por analogia, apresente princípios próprios, além do fato de sua função possibilitar a conexão entre as duas faculdades. Mas não é isso que acontece, e Kant ressalta essa característica do Juízo: por não possuir conceitos e Idéias como o entendimento e a razão possuem respectivamente, ele não possui uma autonomia própria "porque é uma faculdade de meramente subsumir sob conceitos dados, de outra procedência" (cf. Kant 2, p. 37-8; p. 202).

Essa caracterização de Kant é importante na medida em que direciona a função de subsunção do particular sob o universal própria do Juízo aos objetos da natureza. Mas esse direcionamento é feito diferentemente da forma com que o entendimento trabalha com as leis da natureza, determinando-as. A natureza passa a ser um "objeto" do Juízo não objetivamente, mas subjetivamente, ou seja, "dela não se pode fazer nenhum conceito, senão que seu arranjo se orienta segundo nossa faculdade de subsumir leis particulares dadas sob leis mais universais, que no entanto não estão dadas" (Kant 2, p. 38; p. 202). Ora, é exatamente essa característica do Juízo que reintroduz a questão da finalidade: pois o conceito de uma finalidade da natureza, problemático como foi visto, encontra nessa forma de interrogar a natureza a possibilidade de ser investigado. É possível, agora, a Kant, investigar até que ponto essa regra pode ser verificada por meio da subsunção do particular sob o universal e chegar a um novo conceito de natureza que, no entanto, é atinente apenas à forma pela qual o sujeito a pensa, por meio dessa nova faculdade-de-conhecimento.

É esse conceito de natureza que engloba a noção de uma natureza sistemática, ou ainda, na nova forma segundo a qual Kant a denomina: uma experiência como sistema segundo leis empíricas. A nova definição é impor- 
tante para ressaltar a idéia do particular, pois o sistema segundo leis empíricas é o sistema que se constitui por meio da diversidade e heterogeneidade dessas leis. É devido à tamanha diversidade e heterogeneidade que o entendimento não pode dar conta da totalidade sistemática dessas leis, sendo assim tarefa do Juízo possibilitar tal totalidade (cf. Kant 2, p. 38; p. 202). Kant escreve: "Mesmo assim, a experiência particular, inteiramente coerente segundo princípios constantes, precisa também dessa conexão sistemática das leis empíricas, para que se torne possível ao Juízo subsumir o particular sob o universal, embora sempre ainda empírico, e assim por diante, até as leis empíricas mais altas, e as formas da natureza que lhes são conformes" (Kant 2, p. 38; p. 202). Por meio dessa subsunção do Juízo, desse movimento que tem como conseqüência uma ascensão às leis empíricas mais altas, é que começa a se criar um sistema das leis empíricas, no lugar onde havia apenas um agregado das mesmas. Ora, é através do trabalho do Juízo que a natureza começa a tomar um sentido tanto sistemático quanto de finalidade. O Juízo, portanto, na "Primeira introdução", é a faculdade de conhecimento que organiza essa passagem do todo sistemático para uma totalidade sistemática conforme a um fim. No entanto, essa sistematização, que ocorre de acordo com a conformidade das leis, é totalmente contingente do ponto de vista do entendimento, assim como a finalidade é apenas formal e é admitida na natureza apenas em favor do Juízo ${ }^{7}$.

O conceito de natureza, "originariamente proveniente" do Juízo, sistemática e que possui a noção de finalidade, é o de natureza enquanto arte, "em outras palavras, o da técnica da natureza quanto a suas leis particulares, conceito este que não fundamenta nenhuma teoria e, do mesmo modo que a lógica, não contém conhecimento dos objetos e da sua índole, mas somente dá um princípio para a progressão segundo leis de experiência, através do que se torna possível a investigação da natureza" (Kant 2, p. 39; p. 204-5). Ora, a noção de técnica que surge com o Juízo acaba por realizar aquele deslocamento da forma como Kant entendia a unidade sistemática da natureza conforme a um fim. Nas duas primeiras partes da "Primeira introdução", as referências aos problemas que apareciam no Apêndice, em especial a questão da finalidade, são constantes. Se se acompanhar o desenvolvimento delas, percebe-se que é a noção de crítica que começa a ser transformada, pois o Juízo e a noção de reflexão que traz consigo começam a remodelar o sistema. Lebrun, embora esteja aqui preocupado com a questão do gosto, escreve sobre isso: "Preferimos 
pensar que o gênio de Kant está alhures, que a Reflexão é uma outra aventura (o aprofundamento, tornado necessário, da própria noção de Crítica) e que, longe de desvelá-la de maneira contingente, o estudo do gosto inscreve-se nela" (Lebrun 5, p. 396). É importante reter dessa citação a idéia do aprofundamento da crítica tornada possível pela Reflexão. Nessas duas primeiras partes há uma conseqüência desse aprofundamento: surge um sistema da crítica tripartido, em que o Juízo passa a dividir um lugar que anteriormente era destinado apenas ao entendimento e à razão ${ }^{8}$. A partir do momento em que surge esse novo elemento, Kant pode reconstruir a idéia de uma natureza sistemática e a idéia de finalidade. Com o Juízo a crítica se aprofunda e, a partir desse aprofundamento, fica aberta a possibilidade de Kant retornar aos problemas postos pelo Apêndice, aos problemas do supra-sensível, de uma nova maneira.

O Deus em Idéia, conceito da razão que regulava a possibilidade de uma sistematicidade da natureza conforme a um fim, sofre, com essa mudança, um deslocamento: é a partir da noção de técnica da natureza e do Juízo que Kant estrutura o "novo" conceito de natureza. Ora, tal conceito é apresentado por ele também como uma mera idéia, embora modificada pelo novo equilíbrio crítico. Nas palavras de Kant: "Em contrapartida, nosso conceito de uma técnica da natureza, como princípio heurístico no julgamento dela, fará parte da crítica de nossa faculdade de conhecimento, que indica que ocasião temos para fazer-nos uma tal representação dela, que origem tem essa Idéia [grifo nosso] e se ela é encontrável em uma fonte a priori, assim como qual é o âmbito e o limite de seu uso; em suma, tal investigação pertencerá, como parte, ao sistema da crítica da razão pura, mas não à filosofia doutrinal” (Kant 2, p. 40; p. 205).

\footnotetext{
Abstract: Following Gérard Lebrun's thesis in his book Kant and the end of metaphysics the text tries to present a possible connection between the "Appendix to Transcendental Dialetics" of Critique of pure rason and the "First introduction to Critique of Judgement" through the discussion of finality in nature's systematic unity.
}

Key-words: Idea - causality - Judgement - system - criticism 


\section{Notas}

1. As citações das obras de Kant indicam em primeiro lugar as páginas das traduções para o português e em segundo lugar as páginas em alemão segundo a Akademie.

2. Lebrun, acerca disso, afirma: "Em lugar de determinar um ser posto fora do mundo, só se menciona esse ser na medida em que, em relação a 'ele', o mundo é posto como um todo; eu, que faço parte do mundo, adoto 'um ponto de vista' que me permite falar dele como se ele pudesse ser contemplado de fora. Para isso, aproveito a capacidade que o ser racional tem de tornar-se espectador de sua situação, assim como em moral o sujeito 'tem dois pontos de vista de onde ele pode considerar a si mesmo (sich selbst betrachten) (Grundl., IV, 452)" (Lebrun 5, p. 307).

3. Cf.: "Contudo essa ilusão (que podemos evitar que nos engane) é, sem dúvida, inevitavelmente necessária se quisermos ver, além dos objetos que estão em frente dos nossos olhos, também aqueles que estão bem longe, atrás de nós, isto é, quando, no nosso caso, queremos impedir o entendimento para além de qualquer experiência dada (enquanto parte do todo da experiência possível) e, por conseguinte, exercitá-lo para a maior e mais extrema amplitude possível" (Kant 1, p. 534-5; p. 428).

4. Para Lebrun, é justamente pelo fato de Kant ter bem delimitado o uso objetivo da causalidade que lhe é possível, no âmbito supra-sensível, explorar de uma nova maneira o seu sentido transcendental, trabalhando com o mundo sensível de uma maneira não teorética (cf.: Lebrun 5, p. 309).

5. A saber: "Da filosofia como um sistema" e "Do sistema das faculdades superiores do conhecimento, que está no fundamento da filosofia".

6. É importante ressaltar a nota em que Kant discorre sobre a necessidade de chamar os imperativos de habilidade da Fundamentação da metafísica dos costumes, de imperativos técnicos e não problemáticos. Será que Kant não estaria chamando a atenção para a importância do exemplo do médico que conhece bem a sua ciência e tem, de maneira reflexiva, ou seja, a partir do conhecimento que possui, de escolher a melhor forma de curar seus pacientes? (cf. Kant 4, p. 125) Não seria mais uma forma de diferenciá-los dos imperativos categóricos?

7. Cf.: "Essa conformidade a leis, em si contingente (segundo todos os conceitos do entendimento), que o Juízo (somente em favor de si mesmo) presume na natureza e pressupõe nela, é uma finalidade formal da natureza, que admitimos pura e simplesmente nela, mas pela qual não é fundado nem um conhecimento teórico da natureza, nem um princípio prático da liberdade, mas, mesmo assim, é dado, para o julgamento e a investigação da natureza, um princípio para se buscar, para experiências particulares, as leis universais, segundo o qual temos de instaurá-las, para descobrir aquela vinculação sistemática, que é necessária para uma experiência coerente e que temos de admitir a priori” (Kant 2, p. 39). 
8. Ricardo Terra, em seu texto "Reflexão e sistema: as duas Introduções à Crítica do Juízo", aponta essa mudança do sistema da "Primeira Introdução" em relação ao Prefácio da Fundamentação: "O sistema tal como aparece no 'Prefácio' da Fundamentação da metafísica dos costumes é modificado parcialmente, na medida em que agora há a distinção entre o sistema da crítica com três elementos e o da metafísica que continua com dois: a metafísica da natureza e a metafísica dos costumes" (Terra 6, p. 25-6).

\section{Referências Bibliográficas}

1. KANT, I. Crítica da razão pura. Trad. M.P. Santos e A.F. Morujão. Lisboa, Calouste Gulbenkian, 1985. Akademie-Ausgabe. Berlim, Georg Reimer, 1911, Vol. III.

2. _— "Primeira introdução à Crítica do Juízo". In: Duas introduções à Crítica do Juizo. Trad. R.R. Torres Filho. São Paulo, Iluminuras, 1995. Akademie-Ausgabe. Berlim, Walter de Gruyter, 1942, Vol. XX.

3. Prolegômenos a toda metafisica futura que queira apresentar-se como ciência. Trad. A. Morão. Lisboa, Edições 70, 1993. Akademie -Ausgabe. Berlim, Georg Reimer, 1911, Vol. IV.

4. __ "Fundamentação da metafísica dos costumes". In: Crítica da razão pura e outros textos filosóficos. Trad. P. Quintela. São Paulo, Abril Cultural, 1980, Vol. II (col. Os Pensadores).

5. LEBRUN, G. Kant e o fim da metafisica. Trad. C.A.R. Moura. São Paulo, Martins Fontes, 1993.

6. TERRA, R. R. "Reflexão e sistema: as duas introduções à Crítica do Juizo". In: Duas introduções à Crítica do Juizo. São Paulo, Iluminuras, 1995. 